UDC 622.276.43

Author: MUKHAMETSHIN Vyacheslav Sharifullovich, Doctor of Geology and Mineralogy, Professor, Ufa State Petroleum Technological University, Devonskaya St., 54A, Oktyabrsky, Bashkortostan Republic, Russia, 452607,vsh@of.ugntu.ru;

Author: ZEIGMAN Yuriy Veniaminovich, Doctor of Engineering, Professor, Ufa State Petroleum Technological University, Kosmonavtov St., 1, Ufa, Bashkortostan Republic, Russia, 450062, jvzeigman@ya.ru;

Author: ANDREEV Anton Vadimovich, Ph.D. in Engineering, Assistant Professor, Ufa State Petroleum Technological University, Devonskaya St., 54A, Oktyabrsky, Bashkortostan Republic, Russia, 452607,vsh@of.ugntu.ru

\title{
RAPID ASSESSMENT OF DEPOSIT PRODUCTION CAPACITY FOR DETERMINATION OF NANOTECHNOLOGIES APPLICATION EFFICIENCY AND NECESSITY TO STIMULATE THEIR DEVELOPMENT
}

\section{Extended Abstract:}

The subject of research is the process of oil extraction from deposits of the Kushiro-Podolsk age of the Volga-Ural oil and gas province. These are the features of the objects:

- poor reservoir properties of the formation;

- $\quad$ high geological heterogeneity by various parameters;

- $\quad$ closed deposits near oil-water contact surface;

- fissuring and cavern porosity of different degrees;

- wide ranges of values change for geological, physical and chemical properties of layers and fluids saturating them;

- lenticular structure of reservoirs.

Under these conditions the deposits development is often accompanied by:

- intensive reservoir pressure reduction in the absence of water injection into the formation;

- low initial production rates of oil wells and their subsequent substantial decrease within a fairly small period of time due to both reservoir pressure falling and rapid water inrush by lithological windows or by the existing cracks;

- frequent lack of water injection into the reservoir effect of in the form of production rates increase in producing wells, that causes low reserves recovery degree, difficulties for application of secondary and tertiary methods of oil utilization, the high cost of the extracted product. 
Significant resources of these hard-to-recover oil reserves allow considering them as a good chance in hydrocarbon extraction. It is important to assess the need to stimulate the development of these fields. A key issue is the determination of extracted oil reserves and timing of development in reservoir operation on natural modes.

Summing up the experience that concerns development of separate oil deposits being in service for a long time, a rapid assessment method for these indicators at the geologic exploration stage was suggested.

Further technical and economic calculations make it possible:

- to assess the necessity to stimulate the development of facilities similar to those studied by their geological properties;

- to evaluate the efficiency of application of secondary and tertiary methods of oil recovery, including nanotechnological ones;

- to determine the objects development strategy to increase the hydrocarbon resource base.

These problems are proposed to be solved differentially by different groups of homogeneous objects not only in the Volga-Ural province but also in adjacent oil and gas provinces.

Key words: recoverable deposits; development period; oil; oil field; oil production; development; exploitation of deposits, nanotechnologies in an oil recovery.

DOI: dx.doi.org/10.15828/2075-8545-2017-9-3-20-34

MACHINE-READABLE INFORMATION ON CC-LICENSES (HTML-CODE) IN METADATA OF THE PAPER

$<$ a rel="license" href="http://creativecommons.org/licenses/by/4.0/" $><$ img alt="Creative Commons License" style="borderwidth:0" src="https://i.creativecommons.org/l/by/4.0/88x31.png" $/></ \mathrm{a}><$ br $/><$ span xmlns:dct="http://purl.org/ $\mathrm{dc} /$ terms $/$ " property $=" \mathrm{dct}:$ title" $>$ Rapid assessment of deposit production capacity for determination of nanotechnologies application efficiency and necessity to stimulate their development $</$ span $>$ by $<$ a xmlns:cc $=$ "http://creativecommons.org/ ns\#" href="Nanotehnologii v stroitel'stve = Nanotechnologies in Construction. 2017, Vol. 9, no. 3, pp. 20-34. DOI: dx.doi. org/10.15828/2075-8545-2017-9-3-20-34" property="cc:attributionName" rel="cc:attributionURL" $>$ Mukhametshin V.Sh., Zeigman Yu.V., Andreev A.V. $</ a>$ is licensed under a $<$ a rel="license" href="http://creativecommons.org/licenses/ by/4.0/" $>$ Creative Commons Attribution 4.0 International License $</ \mathrm{a}>.<\mathrm{br} />$ Based on a work at $<\mathrm{a}$ xmlns:dct="http:// purl.org/dc/terms/" href=" http://nanobuild.ru/en_EN/nanobuild-3-2017/" rel="dct:source"> http://nanobuild.ru/ en_EN/nanobuild-3-2017/ $</ \mathrm{a}>$. $<$ br $/>$ Permissions beyond the scope of this license may be available at $<\mathrm{a} \times \mathrm{xmlns}: \mathrm{cc}=$ "http: $/ /$ creativecommons.org/ns\#" href="vsh@of.ugntu.ru" rel="cc:morePermissions">vsh@of.ugntu.ru</a>. 


\section{References:}

1. Economides J.M. Reservoir stimulation. J.M. Economides, K.I. Nolte. West Sussex, England: John Wiley and Sons, 2000. 856 p.

2. Muslimov R.Kh. Sovremennye metody povyshenija nefteizvlechenija: proektirovanie, optimizacija i ocenka jeffektivnosti [Modern methods of oil recovery increasing: design, optimization and performance evaluation]. Kazan: FEN, 2005. 688 p. (In Russian).

3. Zeigman Yu.V., Mukhametshin V.Sh., Khafizov A.R. et al. Prospects of Application of Multi-Functional Well Killing Fluids in Carbonate Reservoirs. SOCAR Proceedings, 2016. № 3. P. 33-39.

4. Mukhametshin V.V., Andreev V.E., Dubinsky G.S. et al. The Usage of Principles of System Geological-Technological Forecasting in the Justification of the Recovery Methods. SOCAR Proceedings, 2016. № 3. P. 46-51.

5. Gazizov A.A. Uvelichenie nefteotdachi neodnorodnyh plastov na pozdnej stadii razrabotki [Increase of oil recovery in heterogeneous reservoirs at the late stage of the development]. Moscow. Co Ltd «Nedra-Business-centre», 2002. 639 p. (In Russian).

6. Mukhametshin V.Sh. Model forecast of the oil recovery process using development experience of old-run fields // Neftegazovoe delo. 2011. Vol. 9, № 4. C. 47-50.

7. Viktorin V.D. Razrabotka neftjanyh mestorozhdenij, priurochennyh k karbonatnym kollektoram [Oil deposits within carbonate reservoirs development]. V.D. Viktorin, N.A. Lykov. Moscow, Nedra, 1980. 202 p. (In Russian).

8. Mukhametshin V.V. Obobshhenie opyta provedenija soljano-kislotnyh obrabotok s cel'ju povyshenija jeffektivnosti kontrolja i regulirovanija processa vozdejstvija v uslovijah zalezhej vysokovjazkoj nefti turnejskogo jarusa [Generalization of hydrochloric acid treatment experience to control efficiency increasing and the impact process regulation in high-viscous oil deposits conditions of Tournaisian tier]. Ufa: Ufa State Petroleum Technological University Publishing House, 2005. 114 p. (In Russian).

9. Ibragimov N.G., Musabirov M.Kh., Yartiev A.F. Jeffektivnost' kompleksa tehnologij stimuljacii skvazhin v OAO «Tatneft" [Effectiveness of well stimulation technologies package developed by JSC «Tatneft»]. Oil industry, 2014. № 7 . P. 44-47. (In Russian).

10. Yakupov R.F., Mukhametshin V.Sh. Voprosy jeffektivnosti razrabotki nizkoproduktivnyh karbonatnyh kollektorov na primere turnejskogo jarusa Tujmazinskogo mestorozhdenija [Problem of efficiency of low-productivity carbonate res- 
ervoir development on example of Turnaisian stage of Tuymazinskoye field]. Oil industry, 2013. № 12. P. 106-110. (In Russian).

11. Lozin E.V. Geologija i neftenosnost' Bashkortostana [Geology and oil-bearing capacity of Bashkortostan]. Ufa: BashNIPIneft, 2015. 704 p. (In Russian).

12. Muslimov R.Kh. Razvitie neftegazovogo kompleksa Respubliki Tatarstan do 2020 goda: vozmozhnosti i problemy [Development of the oil-and-gas complex of Republic Tatarstan till 2020: opportunities and problems]. Oil industry, 2005. № 5 . P. 9-15. (In Russian).

13. Mukhametshin V.V. Adaptacija soljano-kislotnogo vozdejstvija (SKV) na zalezhah $\mathrm{v}$ karbonatnyh kollektorah [Adaptation of sulphuric acid treatment on carbonate reservoir layers]. Neftegazovoe delo. 2006. Vol. 4, № 1. P. 127-131. (In Russian)

14. Zeigman Yu.V., Mukhametshin V.Sh., Khafizov A.R. et al. Osobennosti vybora sostavov zhidkostej glushenija skvazhin v oslozhnennyh uslovijah jekspluatacii skvazhin [Peculiarities of selecting well-killing fluids composition for difficult conditions]. Oil industry, 2017. № 1. P. 66-69. (In Russian).

15. Kubarev P.N., Kamyshnikov A.G., Antonov G.P. et al. Rezul'taty trassernyh issledovanij na Bajtuganskom neftjanom mestorozhdenii [Tracer studies results in Baitugan oil field]. Collection of scientific papers of TatNIPIneft. 2013. Iss. 81. P. 108-118. (In Russian).

16. Zeigman Yu.V., Mukhametshin V.V. Obosnovanie sootvetstvija sistem zavodnenija osobennostjam geologicheskogo stroenija zalezhej [The compliance of flooding systems to the geological structure of the deposits justification]. Oilfield engineering, 2009. № 5. P. 10-12. (In Russian).

17. Abyzbaev I.I., Syrtlanov A.Sh., Viktorov P.F. et al. Razrabotka zalezhej s trudnoizvlekaemymi zapasami nefti Bashkortostana. [The development of deposits with hard to recover oil reserves of Bashkortostan]. Ufa. Kitap, 1994. 180 p. (In Russian).

18. Kudinov V.I., Suchkov B.M. Intensifikacija dobychi vjazkoj nefti iz karbonatnyh kollektorov [Stimulation of viscous oil recovery in carbonate reservoirs]. Samara. Book Publisher House, 1996. 438 p. (In Russian).

19. Mukhametshin V.V. O neobhodimosti i sozdanii edinogo kompleksnogo metoda geologo-promyslovogo analiza i obobshhenija jeffektivnosti vozdejstvija na prizabojnuju zonu plasta [The need for creation of a unified comprehensive method of geological and field analysis and integration of data on effective influence on the bottom-hole formation zone]. Oil industry, 2017. № 4. P. 80-84. (In Russian).

20. Zeigman Yu.V., Mukhametshin V.V. Obobshhenie opyta zavodnenija zalezhej vysokovjazkoj nefti v karbonatnyh kollektorah s cel'ju povyshenija jeffektivnosti vozdejstvija na plast [High-viscous oil deposits in carbonate reservoirs flooding expe- 
rience generalization with the aim of the stimulation efficiency increasing]. Ufa. Ufa State Petroleum Technological University Publisher House, 2009. 134 p. (In Russian).

21. Surguchev M.L. Vtorichnye i tretichnye metody uvelichenija nefteotdachi plastov [Secondary and tertiary enhanced oil recovery methods]. Moscow. Nedra, 1985. 308 p. (In Russian).

22. Mukhametshin V.Sh. Ocenka po kosvennym dannym stepeni zagrjaznennosti i vremeni ochistki prizabojnoj zony skvazhin, jekspluatirujushhih zalezhi nefti v karbonatnyh kollektorah [Wells exploiting oil reserves in carbonate reservoirs contamination degree and wellbore zones cleaning timing assessment basing on indirect evidence]. Oil industry. 1990. № 6. P. 11-16. (In Russian).

23. Khayredinov N.Sh., Popov A.M., Mukhametshin V.Sh. Increasing the flooding efficiency of poor-producing oil deposits in carbonate. Oil industry (Neftyanoe khozyastvo), 1992. № 9. P. 18-20.

24. Lin Z. Polymer-induced structural transitions in oleate solutions: microscopy, rheology, and nuclear magnetic resonance studies. Z. Lin, C.D. Eads. Langmuir. 1997. Vol. 13. P. 2647-2654.

25. Kadyrov R.R., Nizaev R.Kh., Yartiev A.F., Mukhametshin V.V. Ogranichenie vodopritoka v gorizontal'nyh skvazhinah na mestorozhdenijah s trudnoizvlekaemymi zapasami nefti [A novel water shut-off technique for horizontal wells at fields with hard-to-recover oil reserves]. Oil industry, 2017. № 5. P. 44-47. (In Russian).

26. Akhmetov R.T., Mukhametshin V.V., Andreev A.V. Interpretacija krivyh kapilljarnogo davlenija pri smeshannoj smachivaemosti [Interpretation of capillary pressure curves in case of mixed-wettability]. Geology, Geophysics and Development of Oil and Gas Fields, 2017. № 4. P. 40-43. (In Russian).

27. Galkin V.I., Alekseev A.O., Solovev S.I. Razrabotka statisticheskoj modeli dlja ocenki stepeni perspektivnosti priobretenija neftjanogo uchastka (na primere territorii Permskogo kraja) [Development of the statistical model to assess the prospects of an oil site acquisition (the Perm region territory is taken as an example)]. Geology, Geophysics and Development of Oil and Gas Fields, 2016. № 1. P. 29-32. (In Russian).

28. Zeigman Y.V., Mukhametshin V.Sh., Sergeev V.V., Kinzyabaev F.S. Experimental study of viscosity properties of emulsion system with $\mathrm{SiO}_{2}$ nanoparticles. Nanotehnologii v stroitel'stve $=$ Nanotehnologies in Construction. 2017, Vol. 9, no. 2, pp. 16-38. DOI: dx.doi.org/10.15828/2075-8545-2017-9-2-16-38. (In Russian).

29. Khisamov R.S., Nasybullin A.V., Latifullin F.M. et al. Jekspress-ocenka na ARM «Lazurit» geologicheskih riskov i ostatochnyh zapasov nefti po planiruemym k 
bureniju proektnym skvazhinam [Geological risks and residual oil reserves by planned for drilling wells on workstation «Lazurit» rapid assessment]. Collection of scientific papers of TatNIPIneft. 2015. Iss. 83. P. 117-123. (In Russian).

30. Tokarev M.A. Kompleksnyj geologo-promyslovyj kontrol' za tekushhej nefteotdachej pri vytesnenii nefti vodoj [Current oil recovery under water-oil displaced comprehensive geological monitoring]. Moscow. Nedra, 1990. 267 p. (In Russian).

31. Andreev A.V., Mukhametshin V.Sh., Kotenev Yu.A. Deposit Productivity Forecast in Carbonate Reservoirs with Hard to Recover Reserves. SOCAR Proceedings, 2016. № 3. P. 40-45.

32. Kanalin V.G., Kapralova M.K. Issledovanie izmenenija kojefficienta produktivnosti pri razrabotke zalezhej nefti Zapadnoj Sibiri [The productivity factor changes study in the Western Siberia oil deposits development]. Oilfield Engineering, 1981. № 11. P. 11-12. (In Russian).

33. Mukhametshin V.V. Ocenka potencial'nyh dobyvnyh vozmozhnostej skvazhin po geologo-geofizicheskim i promyslovym dannym [Estimation of well potential productivity according to field-geological and geophysical data]. Neftegazovoe delo. 2016. Vol. 14. № 2. P. 61-64. (In Russian).

34. Guseva D.N., Zimin P.V., Arzhilovskiy A.V. Sposob ocenki vyrabotki zapasov zrelyh neftjanyh mestorozhdenij [A method to assess reserves recovery from mature oil fields]. Oilfield engineering, 2016. № 12. P. 5-9. (In Russian).

35. Mukhametshin V.V., Andreev V.E., Zeigman Yu.V. et al. Snizhenie riskov prinjatija nizkojeffektivnyh upravljajushhih reshenij pri ispol'zovanii kislotnyh sostavov, predotvrashhajushhih jemul'sioobrazovanie [Reducing risks of low-efficiency decisions during acidization for emulsifying prevention]. Geology, Geophysics and Development of Oil and Gas Fields, 2017. № 5. P. 36-42. (In Russian).

\section{DeAR COLLEAGues!}

THE REFERENCE TO THIS PAPER HAS THE FOLLOWING CITATION FORMAT:

Mukhametshin V.Sh., Zeigman Yu.V., Andreev A.V. Rapid assessment of deposit production capacity for determination of nanotechnologies application efficiency and necessity to stimulate their development. Nanotehnologii v stroitel'stve = Nanotechnologies in Construction. 2017, Vol. 9, no. 3, pp. 20-34. DOI: dx.doi. org/10.15828/2075-8545-2017-9-3-20-34. (In Russian). 
УДК 622.276.43

Автор: МУХАМЕТШИН Вячеслав Шарифуллович, профессор, д.г-м.н., директор филиала ФГБОУ ВО «Уфимский государственный нефтяной технический университет» в г.Октябрьском; ул. Девонская, 54а, г.Октябрьский, Республика Башкортостан, Россия, 452607, vsh@of.ugntu.ru; Автор: ЗЕЙГМАН Юрий Вениаминович, профессор, д.т.н., заведующий кафедрой разработки и эксплуатации нефтегазовых месторождений ФГБОУ ВО «Уфимский государственный нефтяной технический университет»; ул. Космонавтов, 1, г. Уфа, Республика Башкортостан, Россия, 450062, jvzeigman@ya.ru;

Автор: АНДРЕЕВ Антон Вадимович, к.т.н., доцент кафедры разведки и разработки нефтяных и газовых месторождений филиала ФГБОУ ВО «Уфимский государственный нефтяной технический университет» в г.Октябрьском; ул. Девонская, 54a, г.Октябрьский, Республика Башкортостан, Россия, 452607, e-mail: vsh@of.ugntu.ru

\section{ЭКСПРЕСС-ОЦЕНКА ПОТЕНЦИАЛА ДОБЫВНЫХ ВОЗМОЖНОСТЕЙ ЗАЛЕЖЕЙ ДЛЯ ОПРЕДЕЛЕНИЯ ЭФФЕКТИВНОСТИ ПРИМЕНЕНИЯ НАНОТЕХНОЛОГИЙ И НЕОБХОДИМОСТИ СТИМУЛИРОВАНИЯ ВВОДА ИХ В РАЗРАБОТКУ}

\section{АННОТАЦИЯ К СТАТЬЕ (АВТОРСКОЕ РЕЗЮМЕ, РЕФЕРАТ):}

Предметом исследования является процесс извлечения нефти из залежей каширо-подольского возраста Волго-Уральской нефтегазоносной провинции. Особенностями объектов являются:

- низкие коллекторские свойства пластов;

- высокая геологическая неоднородность по различным параметрам;

- запечатанность залежей вблизи поверхности водо-нефтяного контакта;

- наличие различной степени трещиноватости и кавернозности;

- широкие диапазоны изменения значений геолого-физических и физикохимических свойств пластов и насыщающих их флюидов;

- линзовидное строение пород-коллекторов.

В этих условиях часто разработка залежей сопровождается:

- интенсивным снижением пластового давления при отсутствии закачки в пласт воды;

- низкими начальными дебитами нефти скважин и последующим их существенным снижением в течение довольно незначительного периода времени как ввиду падения пластового давления, так и ввиду быстрого прорыва воды либо по литологическим окнам, либо по существующим трещинам; 
- частым отсутствием эффекта от использования закачки в пласт воды в виде увеличения дебитов в добывающих скважинах, что является причиной низкой степени выработки запасов, сложности применения вторичных и третичных методов повышения коэффициента использования нефти, высокой себестоимости добываемой продукции.

Значительные ресурсы этих объектов с трудноизвлекаемыми запасами нефти позволяют рассматривать их как существенный резерв в добыче углеводородного сырья. При этом важно оценить необходимость стимулирования ввода в разработку этих месторождений. Ключевым вопросом при этом является определение извлекаемых запасов нефти и сроков разработки при эксплуатации залежей на естественных режимах.

На основании обобщения опыта разработки отдельных залежей нефти, находящихся длительное время в эксплуатации, предложен экспресс-метод оценки этих показателей на стадии проведения геолого-разведочных работ. Последующее проведение технико-экономических расчетов позволяет:

- оценивать необходимость стимулирования ввода объектов, аналогичных исследованным по геолого-промысловой характеристике в разработку;

- оценивать эффективность применения вторичных и третичных методов увеличения нефтеотдачи, в том числе и с использованием нанотехнологий; - определять стратегию разработки объектов для увеличения ресурсной базы углеводородов.

Решать эти задачи предлагается дифференцированно, по различным группам однородных объектов в пределах не только Волго-Уральской, но и сопредельных нефтегазоносных провинций.

Ключевые слова: извлекаемые запасы; сроки разработки; нефть; месторождение; добыча; разработка; эксплуатация залежей, нанотехнологии в добыче нефти.

DOI: dx.doi.org/10.15828/2075-8545-2017-9-3-20-34

\footnotetext{
МАШИНОЧИТАЕМАЯ ИНФОРМАЦИЯ О СС-ЛИЦЕНЗИИ В МЕТАДАННЫХ СТАТЬИ (НTML-КОД):

$<$ a rel="license" href="http://creativecommons.org/licenses/by/4.0/"><img alt="Лицензия Creative Commons" style="borderwidth:0" src="https://i.creativecommons.org/l/by/4.0/88x31.png" / $></ \mathrm{a}><$ br $/>$ Произведение «<span xmlns:dct="http:// purl.org/dc/terms/" href="http://purl.org/dc/dcmitype/Text" property="dct:title" rel="dct:type"> Экспресс-оценка потенциала добывных возможностей залежей для определения эффективности применения нанотехнологий и необходимости стимулирования ввода их в разработку </span>» созданное автором по имени <a xmlns:cc="http://creativecommons.org/ ns\#" href="Нанотехнологии в строительстве. - 2017. - Том 9, № 3. - С. 20-34. - DOI: dx.doi.org/10.15828/2075-8545-20179-3-20-34" property="cc:attributionName" rel="cc:attributionURL"> Мухаметшин В.Ш., Зейгман Ю.В., Андреев А. В. </ a $>$, публикуется на условиях $<$ a rel="license" href="http://creativecommons.org/licenses/by/4.0/">лицензии Creative Commons «Attribution» ( «Атрибуция») 4.0 Всемирная $</ \mathrm{a}>$. $<\mathrm{br} />$ Основано на произведении c $<\mathrm{a}$ xmlns:dct="http:// purl.org/dc/terms/" href="http://nanobuild.ru/ru_RU/nanobuild-3-2017/" rel="dct:source" >http://nanobuild.ru/ru_RU/ nanobuild-3-2017/</a > . $<$ br $/>$ Разрешения, выходящие за рамки данной лицензии, могут быть доступны на странице $<\mathrm{a}$ xmlns:cc="http://creativecommons.org/ns\#" href="vsh@of.ugntu.ru" rel="cc:morePermissions">vsh@of.ugntu.ru $</ a>$.
} 


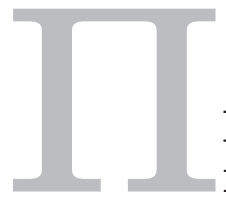

ри налоговом регулировании для целей стимуляции расширения ресурсной базы важно знать потенциал добывных возможностей залежей [1-5]. В большей мере это касается низкопродуктивных объектов, ввод и активная разработка которых сдерживается рамками экономической рентабельности сегодняшнего дня. Одними из таких объектов являются залежи нефти в карбонатных коллекторах ВолгоУральской нефтегазоносной провинции, в которых сосредоточены значительные (около $30 \%$ ) запасы углеводородного сырья [6-10].

Особенностями этих объектов являются:

- низкие коллекторские свойства пластов;

- $\quad$ высокая геологическая неоднородность по различным параметрам;

- запечатанность залежей вблизи поверхности водо-нефтяного контакта;

- $\quad$ наличие различной степени трещиноватости и кавернозности;

- широкие диапазоны изменения значений геолого-физических и физико-химических свойств пластов и насыщающих их флюидов;

- $\quad$ линзовидное строение пород-коллекторов [11-14].

В этих условиях часто разработка залежей сопровождается:

- интенсивным снижением пластового давления при отсутствии закачки в пласт воды;

- низкими начальными дебитами нефти скважин и последующим их существенным снижением в течение довольно незначительного периода времени как ввиду падения пластового давления, так и ввиду быстрого прорыва воды либо по литологическим окнам, либо по существующим трещинам [15-18];

- частым отсутствием эффекта от использования закачки в пласт воды в виде увеличения дебитов добывающих скважин [19-22].

В то же время в отдельных случаях, при правильном выборе очагов под нагнетание воды, удается стабилизировать добычу нефти и повысить коэффициент извлечения нефти (КИН) до $0,3-0,4$, что в $2-3$ раза превышает КИН при условии разработки этих залежей на естественных режимах [23-25].

Всё это требует дифференцированного подхода к управлению разработкой таких сложных и противоречивых объектов, когда высоки 
риски принятия тех или иных решений, а использование традиционных методов разработки позволяют добывать нефть на уровне предела экономической рентабельности. При этом большое значение имеет создание преференций, в том числе и налоговые льготы (или как их разновидность субвенции, или затраты государства в инфраструктурные проекты), для стимулирования нефтяных компаний к использованию этого существенного резерва добычи нефти. Важно при этом также иметь аппарат, позволяющий оценивать эффективность использования нанотехнологий в добыче нефти, что вносит свои коррективы в состав преференций.

В условиях наличия значительного количества неопределенностей при разработке таких объектов важно знать, какой минимум добычи нефти будет обеспечен при использовании традиционных технологий разработки [26]. Причем необходимо, чтобы такая оценка была проведена, как верно отмечается в [27], до составления первых проектных документов, еще лучше до приобретения лицензий недропользователем.

Задача в такой постановке решалась для условий залежей в карбонатных коллекторах каширо-подольского возраста, приуроченных к Бирской седловине и Башкирской вершине. Разработка объектов осуществлялась в основном на естественных режимах, и лишь на отдельных относительно высокопродуктивных участках организована закачка в пласт воды. Результаты заводнения носят противоречивый характер, наряду с получением эффекта наблюдается его полное отсутствие, и даже имеет место отрицательное влияние на процесс выработки запасов.

Объекты с использованием факторного анализа были разбиты на три группы, в пределах которых они близки по геолого-промысловой характеристике.

В границах каждой группы на участках, не охваченных закачкой, изучалось изменение добычи нефти по скважинам в пределах условновыделенных зон дренажа [28] ввиду отсутствия интерференции между скважинами, вплоть до расстояний 250-300 метров между ними. Аналогичные выводы сделаны в работах [29, 30]. Также изучалось влияние на изменение дебитов скважин параметров, определение которых возможно на стадии проведения геолого-разведочных работ.

В практике часто используются значения коэффициентов продуктивности для прогноза дебитов скважин и их изменения во времени [31-33]. Однако «неустойчивость» и изменение этого важного ин- 
тегрального показателя во времени делают его применение сложным, а иногда и проблематичным [34, 35] в плане прогноза извлекаемых запасов нефти $\left(Q_{\text {извл }}\right)$.

Обобщение и анализ геолого-промыслового материала по выделенным группам позволили получить следующие эмпирические уравнения для оценки извлекаемых запасов при разработке залежей на естественном режиме и при плотности сетки скважин 9 га/скв и более:

- для объектов первой группы

$$
Q_{\text {извл }}=N\left(0,91 H_{\text {э }} / \sqrt{n}^{t} \sum_{i=1}^{\text {общ }} 0,141-498 \ln t_{i}\right) \text {; }
$$

- для объектов второй группы

$$
\begin{aligned}
Q_{\text {извл }}=N\left[\left(0,24 \sqrt{H_{э} m_{\Gamma}} / \sqrt{H_{\Pi}}-1,6 \sqrt{\mu_{\text {н }}} / \sqrt[3]{H_{э} / n}+0,93 \sqrt{m_{\Gamma}} / \sqrt[3]{H_{э} / n}\right)\right. & -t_{i=1}^{t} \text { общ } \\
& \left.-\sum_{i=1} 0,124-447 \ln t_{i}\right] ;
\end{aligned}
$$

- для объектов третьей группы

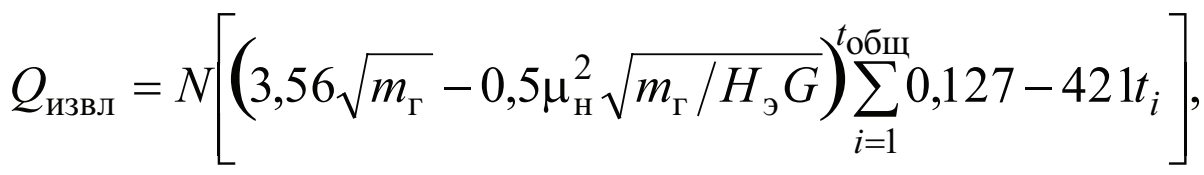

где $t_{i}$ - время с начала эксплуатации скважин, год;

$t_{\text {общ }}-$ общий срок эксплуатации скважин до предела экономической рентабельности, год;

$H_{\text {э }}$ - среднее значение эфрективной нефтенасыщенной толщины пласта, м;

$H_{\text {п }}$ среднее значение толщины нефтенасыщенных пропластков, м;

$m_{\text {г }}$ - среднее значение пористости пласта;

$n$ - среднее количество нефтенасыщенных пропластков;

$\mu_{\text {н }}$ - вязкость пластовой нефти, мПа • с;

$G$ - газосодержание пластовой нефти, $\mathrm{m}^{3} / \mathrm{T}$;

$N$ - количество планируемых добывающих скважин.

По фактическим данным $t_{\text {общ }}$ с достаточной степенью точности определяется из уравнений:

- для объектов первой группы

$$
t_{\text {общ }}=498 e^{-0,141 Q_{\mathrm{H} \min } / 0,91 H_{\ni} / \sqrt{n}} ;
$$


• для объектов второй группы

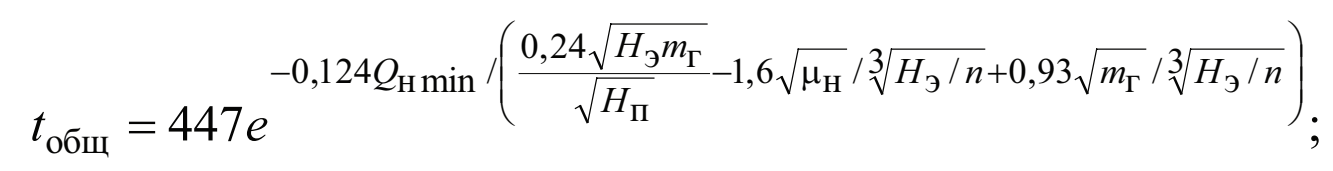

- для объектов третьей группы

$$
t_{\text {общ }}=421 e^{-0,127 Q_{\mathrm{H} \min } /\left(3,56 \sqrt{m_{\Gamma}}-0,5 \mu_{\mathrm{H}}^{2} \sqrt{m_{\Gamma} / H_{\ni} G}\right)},
$$

где $\boldsymbol{Q}_{\text {н min }}$ - минимально рентабельный дебит, т/год.

Таким образом, проведенные исследования позволили получить экспресс-метод оценки извлекаемых запасов нефти и сроков эксплуатации с использованием параметров, определение которых возможно на стадии проведения геолого-разведочных работ с достаточной степенью точности. Метод позволяет после проведения технико-экономических расчетов:

- определять необходимость стимулирования ввода в разработку залежей с трудноизвлекаемыми запасами;

- оценивать эффективность применения вторичных и третичных методов увеличения нефтеотдачи, в том числе с использованием нанотехнологий;

- определять стратегию разработки объектов для расширения ресурсной базы углеводородов.

\section{Библиографический список:}

1. Economides J.M. Reservoir stimulation / J.M. Economides, K.I. Nolte. West Sussex, England: John Wiley and Sons, 2000. 856 p.

2. Муслимов P.X. Современные методы повышения нефтеизвлечения: проектирование, оптимизация и оценка эффективности. - Казань: ФЭН, 2005. - 688 с.

3. Prospects of Application of Multi-Functional Well Killing Fluids in Carbonate Reservoirs / Yu.V. Zeigman, V.Sh. Mukhametshin, A.R. Khafizov et al. // SOCAR Proceedings. 2016. № 3. P. 33-39.

4. The Usage of Principles of System Geological-Technological Forecasting in the Justification of the Recovery Methods / V.V. Mukhametshin, V.E. Andreev, G.S. Dubinsky et al. // SOCAR Proceedings, 2016. № 3. P. 46-51. 
5. Газизов А.А. Увеличение нефтеотдачи неоднородных пластов на поздней стадии разработки. - М.: ООО «Недра-Бизнесцентр», 2002. - 639 с.

6. Мухалетшин В.Ш. Моделирование процесса нефтеизвлечения с использованием опыта разработки месторождений, находящихся длительное время в эксплуатации // Нефтегазовое дело. - 2011. - Т. 9, № 4. - С. 47-50.

7. Викторин В.Д. Разработка нефтяных месторождений, приуроченных к карбонатным коллекторам / В.Д. Викторин, Н.А. Лыков. - М.: Недра, 1980. - 202 с.

8. Мухалетшин В.В. Обобщение опыта проведения соляно-кислотных обработок с целью повышения эффективности контроля и регулирования процесса воздействия в условиях залежей высоковязкой нефти турнейского яруса. - Уфа: Изд-во УГНТУ, 2005. - $114 \mathrm{c}$.

9. Ибрагилов Н.Г. Эффективность комплекса технологий стимуляции скважин в ОАО «Татнефть» / Н.Г. Ибрагимов, М.Х. Мусабиров, А.Ф. Яртиев // Нефтяное хозяйство. -2014 . - № 7. - С. 44-47.

10. Якупов Р.Ф. Вопросы эффективности разработки низкопродуктивных карбонатных коллекторов на примере турнейского яруса Туймазинского месторождения / Р.Ф. Якупов, В.Ш. Мухаметшин // Нефтяное хозяйство. - 2013. - №12. - С. 106110.

11. Лозин Е.В. Геология и нефтеносность Башкортостана. - Уфа: БашНИПИнефть, 2015. - $704 \mathrm{c}$.

12. Муслилов P.X. Развитие нефтегазового комплекса Республики Татарстан до 2020 года: возможности и проблемы // Нефтяное хозяйство. - 2005. - № 5. - С. 9-15.

13. Мухалетшин В.В. Адаптация соляно-кислотного воздействия (СКВ) на залежах в карбонатных коллекторах / Нефтегазовое дело. - 2006. - Т. 4, № 1. - С. 127-131.

14. Особенности выбора составов жидкостей глушения скважин в осложненных условиях эксплуатации скважин / Ю.В. Зейгман, В.Ш. Мухаметшин, А.Р. Хафизов и др. // Нефтяное хозяйство. - 2017. - № 1. - С. 66-69.

15. Результаты трассерных исследований на Байтуганском нефтяном месторождении / П.Н. Кубарев, А.Г. Камышников, Г.П. Антонов и др. / Сборник научных трудов ТатНИПИнефть. - 2013. - Вып. 81. - С. 108-118.

16. Зейглан Ю.В. Обоснование соответствия систем заводнения особенностям геологического строения залежей / Ю.В. Зейгман, В.В. Мухаметшин // Нефтепромысловое дело. - 2009. - № 5. - С. 10-12.

17. Разработка залежей с трудноизвлекаемыми запасами нефти Башкортостана / И.И. Абызбаев, А.Ш. Сыртланов, П.Ф. Викторов и др. - Уфа: Китап, 1994. $180 \mathrm{c}$.

18. Кудинов В.И. Интенсификация добычи вязкой нефти из карбонатных коллекторов / В.И. Кудинов, Б.М. Сучков. - Самара: Кн. Изд-во, 1996. - 438 с. 
19. Мухалетшин В.В. О необходимости и создании единого комплексного метода геолого-промыслового анализа и обобщения эффективности воздействия на призабойную зону пласта // Нефтяное хозяйство. - 2017. - № 4. - С. 80-84.

20. Зейглан Ю.В. Обобщение опыта заводнения залежей высоковязкой нефти в карбонатных коллекторах с целью повышения эффективности воздействия на пласт / Ю.В. Зейгман, В.В. Мухаметшин. - Уфа: Изд-во УГНТУ, 2009. - 134 с.

21. Сургучев М.Л. Вторичные и третичные методы увеличения нефтеотдачи пластов. М.: Недра, 1985. - 308 с.

22. Мухалетшин В.Ш. Оценка по косвенным данным степени загрязненности и времени очистки призабойной зоны скважин, эксплуатирующих залежи нефти в карбонатных коллекторах // Нефтяное хозяйство. - 1990. - № 6. - С. 11-16.

23. Хайрединов Н.Ш. Повышение эффективности заводнения низкопродуктивных залежей нефти в карбонатных коллекторах / Н.Ш. Хайрединов, А.М. Попов, В.Ш. Мухаметшин // Нефтяное хозяйство. - 1992. - № 9. - С. 18-20.

24. Lin Z. Polymer-induced structural transitions in oleate solutions: microscopy, rheology, and nuclear magnetic resonance studies / Z. Lin, C.D. Eads // Langmuir. 1997. Vol. 13. P. 2647-2654.

25. Ограничение водопритока в горизонтальных скважинах на месторождениях с трудноизвлекаемыми запасами нефти / Р.P. Кадыров, Р.Х. Низаев, А.Ф. Яртиев, В.В. Мухаметшин // Нефтяное хозяйство. - 2017. - № 5. - С. 44-47.

26. Ахлетов P.T. Интерпретация кривых капиллярного давления при смешанной смачиваемости / Р.Т. Ахметов, В.В. Мухаметшин, А.В. Андреев // Геология, геофизика и разработка нефтяных и газовых месторождений. -2017 . - № 4. - С. 4043.

27. Галкин В.И. Разработка статистической модели для оценки степени перспективности приобретения нефтяного участка (на примере территории Пермского края) / В.И. Галкин, А.О. Алексеев, С.И. Соловьев // Геология, геофизика и разработка нефтяных и газовых месторождений. - 2016. - № 1. - С. 29-32.

28. Зейглан Ю.В., Мухаметшин В.ШІ., Сергеев В.В., Кинзябаев Ф.С. Экспериментальное исследование вязкостных свойств эмульсионных систем с содержанием наночастиц $\mathrm{SiO}_{2} / /$ Нанотехнологии в строительстве. - 2017. - Том 9. -№ 2. - С. 1638. - DOI: dx.doi.org/10.15828/2075-8545-2017-9-2-16-38.

29. Экспресс-оценка на АРM «Лазурит» геологических рисков и остаточных запасов нефти по планируемым к бурению проектным скважинам / Р.С. Хисамов, А.В. Насыбуллин, Ф.М. Латифуллин и др. // Сборник научных трудов ТатНИПИнефть. 2015. - Вып. 83. - С. 117-123.

30. Токарев M.A. Комплексный геолого-промысловый контроль за текущей нефтеотдачей при вытеснении нефти водой. - М.: Недра, 1990. - 267 с. 
31. Andreev A.V. Deposit Productivity Forecast in Carbonate Reservoirs with Hard to Recover Reserves / A.V. Andreev, V.Sh. Mukhametshin, Yu.A Kotenev // SOCAR Proceedings, 2016. № 3. P. 40-45.

32. Каналин В.Г. Исследование изменения коэффициента продуктивности при разработке залежей нефти Западной Сибири / В.Г. Каналин, М.К. Капралова // Нефтепромысловое дело. - 1981. - №11. - С. 11-12.

33. Мухалетшин В.В. Оценка потенциальных добывных возможностей скважин по геолого-геофизическим и промысловым данным // Нефтегазовое дело. - 2016. Т. 14, № 2. - С. 61-64.

34. Гусева Д.Н. Способ оценки выработки запасов зрелых нефтяных месторождений / Д.Н. Гусева, П.В. Зимин, А.В. Аржиловский / Н Нефтепромысловое дело. - 2016. № 12. - С. 5-9.

35. Снижение рисков принятия низкоэффективных управляющих решений при использовании кислотных составов, предотвращающих эмульсиообразование / В.В. Мухаметшин, В.Е. Андреев, Ю.В. Зейгман и др. // Геология, геофизика и разработка нефтяных и газовых месторождений. - 2017. - № 5. - С. 36-42.

\section{УВАЖАЕМЫЕ КОЛЛЕГИ!}

ПРИ ИСПОЛЬЗОВАНИИ МАТЕРИАЛА ДАННОЙ СТАТЬИ

ПРОСИМ ДЕЛАТЬ БИБЛИОГРАФИЧЕСКУЮ ССЫЛКУ НА НЕЁ:

Мухалетшин В.Ш., Зейглан Ю.В., Андреев А. В. Экспресс-оценка потенциала добывных возможностей залежей для определения әффективности применения нанотехнологий и необходимости стимулирования ввода их в разработку // Нанотехнологии в строительстве. - 2017. - Том 9, № 3. - C. 20-34. - DOI: dx.doi.org/10.15828/2075-8545-2017-9-3-20-34.

\section{DeAR COLleagues!}

THE REFERENCE TO THIS PAPER HAS THE FOLLOWING CITATION FORMAT:

Mukhametshin V.Sh., Zeigman Yu.V., Andreev A.V. Rapid assessment of deposit production capacity for determination of nanotechnologies application efficiency and necessity to stimulate their development. Nanotehnologii v stroitel'stve = Nanotechnologies in Construction. 2017, Vol. 9, no. 3, pp. 20-34. DOI: dx.doi. org/10.15828/2075-8545-2017-9-3-20-34. (In Russian). 